\title{
Induced pluripotent stem cells from patients with focal cortical dysplasia and refractory epilepsy
}

\author{
DANIEL RODRIGO MARINOWIC ${ }^{1,2}$, FERNANDA MAJOLO ${ }^{2}$, ALESSANDRA DEISE SEBBEN $^{1,2}$, \\ VINICIUS DUVAL DA SILVA ${ }^{3,4}$, TIAGO GIULIANI LOPES ${ }^{3}$, ELISEU PAGLIOLI ${ }^{5}$, ANDRÉ PALMINI ${ }^{4,5}$, \\ DENISE CANTARELLI MACHADO ${ }^{1-3}$ and JADERSON COSTA DA COSTA ${ }^{1,4}$
}

\author{
${ }^{1}$ Brain Institute of Rio Grande do Sul (BraIns); ${ }^{2}$ Institute for Biomedical Research; ${ }^{3}$ Laboratory of Pathological Anatomy; \\ ${ }^{4}$ Postgraduate Program in Medicine and Health Sciences; ${ }^{5}$ Epilepsy Surgery Program, \\ Pontifical Catholic University of Rio Grande do Sul, Porto Alegre, RS 90610000, Brazil
}

Received October 26, 2016; Accepted January 16, 2017

DOI: $10.3892 / \mathrm{mmr} .2017 .6264$

\begin{abstract}
Focal cortical dysplasia (FCD) is caused by numerous alterations, which can be divided into abnormalities of the cortical architecture and cytological variations; however, the exact etiology of FCD remains unknown. The generation of induced pluripotent stem cells (iPSCs) from the cells of patients with neurological diseases, and their subsequent tissue-specific differentiation, serves as an invaluable source for testing and studying the initial development and subsequent progression of diseases associated with the central nervous system. A total of 2 patients demonstrating seizures refractory to drug treatment, characterized as FCD Type IIb, were enrolled in the present study. Fibroblasts were isolated from residual skin fragments obtained from surgical treatment and from brain samples obtained during surgical resection. iPSCs were generated following exposure of fibroblasts to viral vectors containing POU class 5 homeobox 1 (OCT4), sex determining region Y-box 2 (SOX2), Kruppel-like factor 4 and $c-M Y C$ genes, and were characterized by immunohistochemical staining for the pluripotent markers homeobox protein NANOG, SOX2, OCT4, TRA1-60 and TRA1-81. The brain samples were tested with antibodies against protein kinase B (AKT), phosphorylated-AKT, mechanistic target of rapamycin (mTOR) and phosphorylated-mTOR. Analysis of the AKT/mTOR pathway revealed a statistically significant
\end{abstract}

Correspondence to: Dr Jaderson Costa da Costa, Brain Institute of Rio Grande do Sul (BraIns), Pontifical Catholic University of Rio Grande do Sul, 6690 Avenida Ipiranga, Porto Alegre, RS 90610000, Brazil

E-mail: jcc@pucrs.br

Abbreviations: FCD, focal cortical dysplasia; mTOR, mechanistic target of rapamycin; PI3K, phosphoinositide-3-dependent kinase; AKT, protein kinase B; iPSC, induced pluripotent stem cell; DMEM, Dulbecco's modified Eagle's medium

Key words: focal cortical dysplasia, refractory epilepsy, induced pluripotent stem cells, cellular model difference between the cerebral tissues of the two patients, which were of different ages (45 and 12 years old). Clones with the morphological features of embryonic cells were detected on the 13th day and were characterized following three subcultures. The positive staining characteristics of the embryonic cells confirmed the successful generation of iPSCs derived from the patients' fibroblasts. Therefore, the present study presents a method to obtain a useful cellular source that may help to understand embryonic brain development associated with FCD.

\section{Introduction}

Focal cortical dysplasia (FCD) is the most frequent malformation of cortical development, which may result in drug-refractory epilepsy (1). The frequency of FCD in patients submitted to surgery for refractory epilepsy varies between 12 and $40 \%(2,3)$. A definitive diagnosis of FCD is generally made following surgical treatment for refractory epilepsy, based on neuropathological findings of the resected cortical tissue (4). FCD is characterized by numerous alterations, which may be divided into two major groups. The first group is characterized by abnormalities of the cortical architecture through columnar disorganization and laminar interruption, which is observed by alterations in the composition of the sixth tangential layer. The second group is defined by cytological abnormalities, with hypertrophic neuronal cells observed outside the normal anatomic location at layer $\mathrm{V}$ and/or the presence of balloon cells. Balloon cells possess a poorly defined membrane with single or multiple nuclei and an eosinophilic cytoplasm, which are characteristics of neuronal and glial cells; this condition is primarily diagnosed as Taylor's FCD or FCD Type IIb $(5,6)$.

In 2004, Palmini et al (1) classified FCD according to the white matter and cortical layer architecture as follows: Type I, presence of heterotrophic neurons in the white matter, cortical layer architecture alteration and giant neurons; Type IIa, presence of heterotrophic neurons in the white matter, cortical layer architecture alterations, giant neurons and dysmorphic cells; Type IIb, presence of heterotrophic neurons in the white matter, cortical layer architecture alterations, giant neurons, dysmorphic cells and presence of balloons cells. In 2011, 
Blumcke et al (7) modified the Palmini et al (1) classification, defining three types of FCD, known as Type I, II and III, where the Type III was characterized by presence of abnormalities associated with principal lesion, for example hippocampal sclerosis, glial or glio-neuronal tumor, vascular malformation, trauma, ischemic injury and encephalitis. However, at present, the mechanisms involved in the pathogenesis of FCD have been poorly investigated, which is primarily due to the limited number of cases and the lack of suitable experimental models (5).

The exact etiology of FCD remains unknown; however, it may be associated with clonal somatic mutations that, in certain patients, affect the same signaling pathways (8). Previous studies have demonstrated an increase in mechanistic target of rapamycin (mTOR) signaling in patients with FCD based on the observation of phosphorylated molecules, including S6 ribosomal proteins $(8,9)$. These alterations are primarily observed in FCD Type IIb, with 80-90\% of balloon cells and giant neurons in the cerebral cortex demonstrating increased mTOR signaling (9). Certain cases of FCD demonstrate activation (phosphorylation) of molecules associated with the phosphoinositide-3-dependent kinase (PI3K) and protein kinase B (AKT) pathways in the dysplastic tissue (10). The phosphorylation of molecules involved in the PI3K pathway in response to certain stimuli is associated with a coordinated set of events that control cell growth, cell cycle progression, cell migration and cell survival (11).

The study of neurological and neuropsychiatric disorders has been a longstanding challenge for researchers. Despite significant investments in the field, pre-clinical models suitable for studies concerning pathophysiology, mechanisms and therapeutic targets, and for testing novel drugs, are scarce (12). Although animal models are valuable to elucidate disease mechanisms, develop specific markers and identify genes associated with certain diseases, they have a poor record when it comes to translating therapeutic discoveries for human clinical application (13). The importance of the use of human cells for the study of diseases is evident, given that a high number of drugs that have demonstrated efficacy and safety when tested in animal models fail in clinical trials, which is attributed to differences between the species (14). Studies using post-mortem tissues provide useful insight into cerebral structural alterations that occur at molecular and cellular levels. Considering these surveys and limitations, it is clear that the study of cerebral development would benefit from using the patient's own cells (12).

The reprogramming of adult somatic cells at the embryonic level is a promising approach for regenerative medicine, which may also facilitate in vitro studies to gain an improved understanding of complex genetic diseases. It is possible to reprogram somatic cells by nuclear transfer into enucleated oocytes or by cell fusion between somatic cells and embryonic cells, co-culture of undifferentiated cells with somatic cells, and adding genes that activate selective transcription factors $(15,16)$. In 2006, Takahashi and Yamanaka (17) introduced a novel technique for producing pluripotent cells by reprogramming mouse fibroblasts, which was subsequently applied to human cells in 2007 (18). The cells were reprogrammed with the addition of four genes, POU class 5 homeobox 1 (OCT4), sex determining region Y-box 2 (SOX2),
Kruppel-like factor 4 (KLF4) and $c-M Y C$, using viral vectors. It is possible to perform this reprogramming in various cell types. The cells generated by this method are known as induced pluripotent stem cells (iPSCs) and are similar to embryonic stem cells, with the same self-renewal and differentiation potential characteristics for cells of the three germ layers $(17,19)$.

iPSCs differentiated into specific tissues are now widely used for translational studies testing drugs in cells that are difficult to obtain, including cardiomyocytes, neurons and liver cells. The generation of iPSCs from cells of patients with neurological diseases, and their tissue-specific differentiation, serves as an invaluable source for testing and provides the additional capacity to study the initial development and progression of diseases associated with the central nervous system (20). Cellular models exhibit high relevance for the study of human diseases, providing excellent conditions for understanding mechanisms and constituting an effective tool for high-throughput experiments, even allowing for the construction of platforms for screening novel drugs to treat numerous human diseases (12).

Numerous studies have employed iPSCs for the study of neurological diseases, including for multiple sclerosis (21), cerebellar atrophy (22), Alzheimer's disease (23-26), Rett syndrome (27-30), amyotrophic lateral sclerosis (31-34), ataxia telangiectasia (35), Dravet syndrome (36), familial dysautonomia (37), fragile X syndrome (38), Gaucher's disease (39), Huntington's disease $(40,41)$, Lesch-Nyhan syndrome (42), microcephaly (43), Parkinson's disease (44-46) and schizophrenia (47-49). The technology of cellular reprogramming has highlighted the reality of the clinical heterogeneity observed in patients from the lab bench to the bedside (14). The use of iPSCs derived from patients with specific neural diseases helps provide information regarding embryonic neurogenesis, cortical formation and pathophysiology. Therefore, the present study aimed to establish a cellular model of refractory epilepsy by generating iPSCs from fibroblasts obtained from patients with FCD.

\section{Materials and methods}

Ethics statement. The present study was reviewed and approved by the Committee of Research Ethics of the Pontifical Catholic University of Rio Grande do Sul (approval no. 17943213.9.0000.5336) through the system Platafoma Brasil. Written informed consent was obtained from patient 1 and from the parents of patient 2 (a minor) enrolled in the present study, according to Brazil Resolution no. 466/12.

Patients. A total of 2 patients were enrolled in the present study upon signing the ethical consent form, according to the guidance of the Committee of Research Ethics. Patient 1 was a 45-year-old man with medically refractory seizures, whose electroencephalogram monitoring demonstrated sharp waves in the right frontal region and 3 seizures with onset in the same region (Fig. 1A). Magnetic resonance imaging revealed a small right frontal lesion with an increased signal and blurring of the cortico-subcortical white matter (Fig. 1B), which was resected under acute electrocorticography. Histopathology (Fig. 1C and D) and immunohistochemistry (Fig. 1E and F) revealed 
cortical dyslamination and large, dysplastic neurons, with balloon cells, which is compatible with a diagnosis of FCD Type IIb (International League Against Epilepsy) (7).

Patient 2 was a 12-year-old girl who first started experiencing seizures at the age of $\sim 5$ years, which were characterized by sudden extension of the right arm and head drop. The patient often had numerous seizures per day, despite attempts to treat the seizures with several antiepileptic drug regimens. The patient also had a cystic lesion with regular borders in the right parietal region, which intermittently led to moderate intracranial hypertension and was surgically targeted on several occasions. However, this approach did not significantly improve seizure control, which led to presurgical evaluation. The latter revealed maximal interictal and ictal epileptic activity in the left frontal region (Fig. 1G), where an orbitofrontal dysplastic lesion was clearly observed by magnetic resonance imaging (Fig. $1 \mathrm{H})$. The patient underwent resective surgery under acute electrocorticography, and histopathology (Fig. 1I and J) and immunohistochemistry (Fig. 1K and L) revealed a typical pattern of FCD Type IIb (International League Against Epilepsy) (7).

Production of fibroblasts from skin biopsies. The human fibroblasts were obtained from residual skin fragments from two patients that underwent surgical treatment for medically refractory epilepsy (Epilepsy Surgery Program) at São Lucas Hospital (Porto Alegre, Brazil) on November 2013 (patient 1) and April 2015 (patient 2) at Pontifical Catholic University (Porto Alegre, Brazil). The skin biopsies were cut into $\sim 5 \mathrm{~mm}^{2}$ sections and the skin fragments were placed in a 60-mm Petri dish, with the dermis facing the plate. The cells were cultured in Dulbecco's modified Eagle's medium (DMEM; Gibco; Thermo Fisher Scientific, Inc., Waltham, MA, USA) supplemented with $20 \%$ fetal bovine serum (FBS; Gibco; Thermo Fisher Scientific, Inc.), $100 \mathrm{U} / \mathrm{ml}$ penicillin (Gibco; Thermo Fisher Scientific, Inc.), $100 \mathrm{U} / \mathrm{ml}$ streptomycin (Gibco; Thermo Fisher Scientific, Inc.), $100 \mu \mathrm{g} / \mathrm{ml}$ gentamicin (Gibco; Thermo Fisher Scientific, Inc.) and $20 \mathrm{ng} / \mathrm{ml}$ fibroblast growth factor (Thermo Fisher Scientific, Inc.). The skin fragments were maintained at $37^{\circ} \mathrm{C}$ with $5 \% \mathrm{CO}_{2}$ until reaching $>80 \%$ confluence, and a mycoplasma test (MycoAlert Plus; Lonza Group, Ltd., Basel, Switzerland) was performed. Once the cells were confirmed to be mycoplasma-free, they were maintained under the same conditions up to the seventh passage. Cells in the fourth, fifth, sixth and seventh passages were cryopreserved in liquid nitrogen. In addition, fibroblasts morphological profile was observed by the fifth-passage using an optical microscope Axiovert 25 (Carl Zeiss, Oberkochen, Germany) in bright field.

Histologic analysis of dysplastic tissue. Brain samples obtained via surgical resection were immediately fixed in $10 \%$ buffered formaldehyde for $24 \mathrm{~h}$ at room temperature, and the surgical specimens were processed and paraffin-embedded. All specimens were cut into $5 \mu \mathrm{m}$ sections with a microtome (Leica Microsystems GmbH, Wetzlar, Germany) and stained with hematoxylin and eosin, and additional slides were submitted to automated 3,3-diaminobenzidine (DAB; Dako Autostainer Link 48; Agilent Technologies, Inc., Santa Clara, CA, USA) immunohistochemical staining using 5\% FBS (Gibco; Thermo Fisher Scientific, Inc.), 1\% bovine serum albumin (BSA; Sigma-Aldrich; Merck Millipore, Darmstadt, Germany) and 0,2\% of Triton X-100 (Sigma-Aldrich; Merck Millipore) with blocking buffer for $1 \mathrm{~h}$ at room temperature for anti-NeuN antibody (cat. no. ABN91; Merck Millipore) and anti-vimentin (cat. no. GA630, Dako, Glostrup, Denmark) diluted in blocking buffer (1:100). All reactions included positive and negative external control samples on the same slide. The slides were reviewed under a Zeiss Axiokop 40 microscope (Carl Zeiss Group,). All images were documented in TIFF uncompressed format with a Retiga 2000R color video camera (QImaging, Surrey, Canada).

Generation of iPSCs. iPSCs were generated through exposure of fibroblasts to viral vectors containing the genes OCT4, SOX2, KLF4 and $c$-MYC using the CytoTune ${ }^{\circledR}$-iPS 2.0 Sendai Reprogramming kit (Thermo Fisher Scientific, Inc.) according to the manufacturer's protocol. The CytoTune 2.0 Sendai reprogramming vectors in this kit are based on a modified, non-transmissible form of Sendai virus, which has the Fusion protein $(\mathrm{F})$ deleted, rendering the virus incapable of producing infectious particles from infected cells. Fibroblasts were cultured in 6 -well plates and when $\sim 70 \%$ confluence was reached they were used for transfection. The number of viral particles used was calculated according to the multiplicity of infection (MOI) equation $\left(1.5 \times 10^{6}\right.$ cells at $\mathrm{MOI}=5-5-5-3$; i.e., hOct4 MOI=5, hSox 2 MOI=5, hc-Myc MOI=5, hKlf4 MOI=3). The specific amount of virus was diluted in $1 \mathrm{ml} \mathrm{DMEM} / \mathrm{F} 12$ culture medium supplemented with $20 \%$ Knockout Serum Replacement (Gibco; Thermo Fisher Scientific, Inc.), 1X non-essential amino acids of DMEM (Gibco; Thermo Fisher Scientific, Inc.), 1X Glutamax (Gibco; Thermo Fisher Scientific, Inc.), $100 \mathrm{U} / \mathrm{ml}$ of penicillin (Gibco; Thermo Fisher Scientific, Inc.), $100 \mathrm{U} / \mathrm{ml}$ streptomycin (Gibco; Thermo Fisher Scientific, Inc.) and $100 \mu \mathrm{g} / \mathrm{ml}$ of gentamicin (Gibco; Thermo Fisher Scientific, Inc.). The fibroblasts were exposed to the medium containing the virus and incubated at $37^{\circ} \mathrm{C}$ with $5 \% \mathrm{CO}_{2}$ for $24 \mathrm{~h}$. The cells were washed with PBS and cultured under the same conditions for 6 days. On day 7 following transfection, the cell cultures were treated with trypsin/ethylenediaminetetraacetic acid and transferred to a culture dish containing BD Matrigel hESC-qualified Matrix (BD Biosciences, Franklin Lakes, NJ, USA). Following culture for $24 \mathrm{~h}$, the culture medium was replaced with embryonic cell mTeSR medium (Stemcell Technologies, Inc., Vancouver, Canada). Cell clones were manually removed 20 days later and transferred to new plates containing BD Matrigel hESC-qualified Matrix. Following three subcultures, the clones were characterized by immunostaining with antibodies against homeobox protein NANOG (cat. no. MABD24A4, Merck Millipore) FITC conjugate, SOX2 (cat. no. MAB4423C3, Merck Millipore) Cy3 conjugate, OCT4 (cat. no. MAB4419A4, Merck Millipore) FITC conjugate, TRA1-60 (cat. no. MAB4360C3, Merck Millipore) Cy3 conjugate and TRA1-81 (cat. no. MAB4381C3, Merck Millipore) Cy3 conjugate following the addition of $4 \%$ paraformaldehyde. The culture was incubated for $1 \mathrm{~h}$ at room temperature with blocking buffer [5\% FBS, $1 \%$ of BSA and $0.2 \%$ of Triton X-100 (Sigma-Aldrich; Merck Millipore)] for NANOG, SOX2 and OCT4 antibodies. The same blocking buffer without Triton was used when cell surface proteins were analyzed 
A

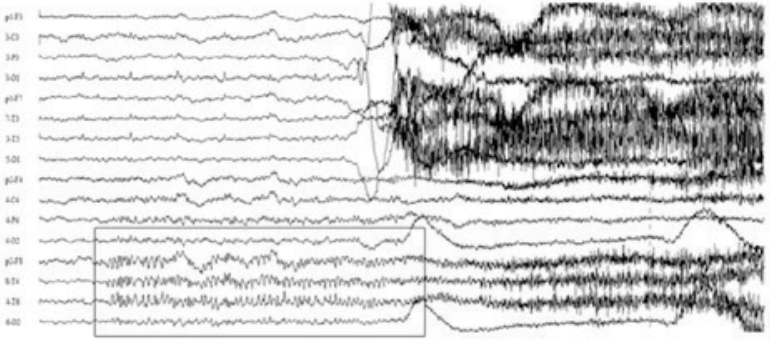

C

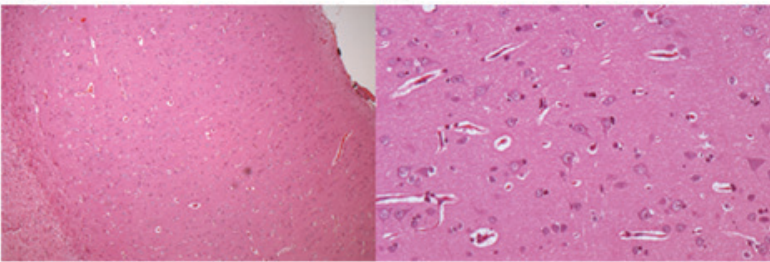

G

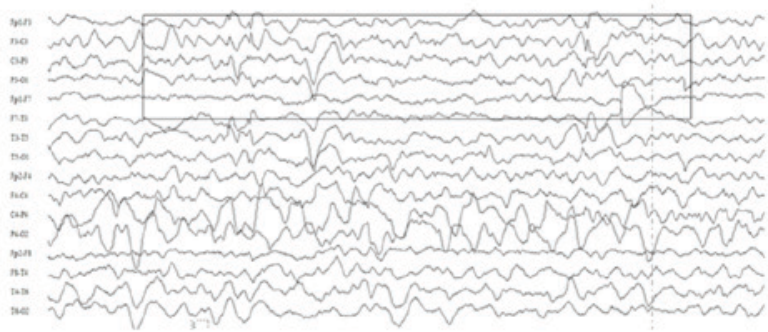

I

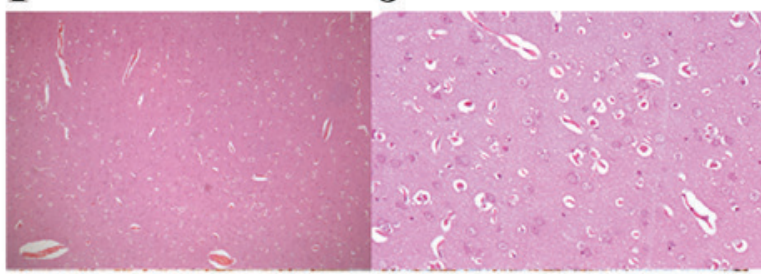

B
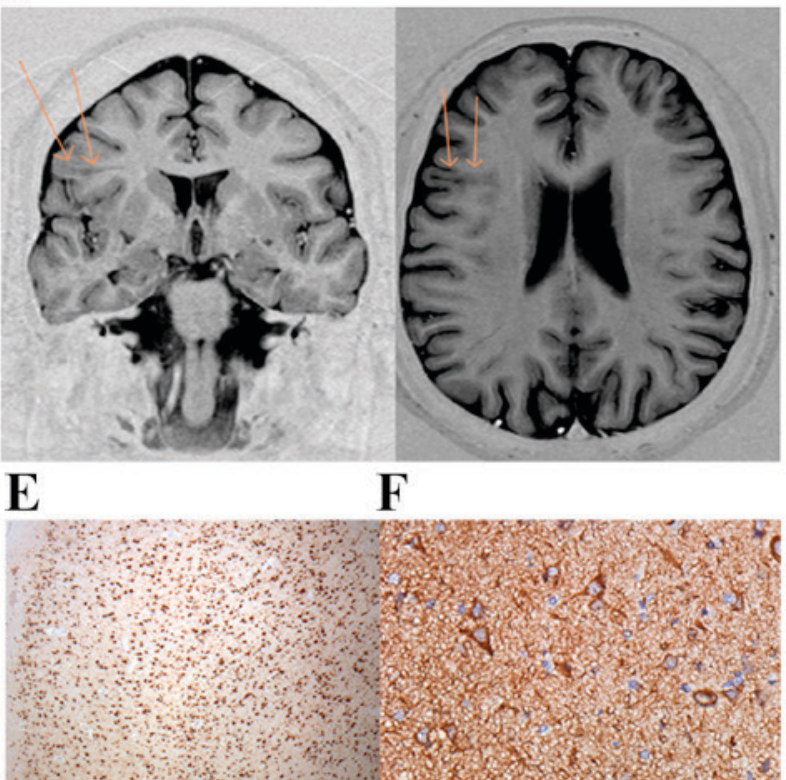

H

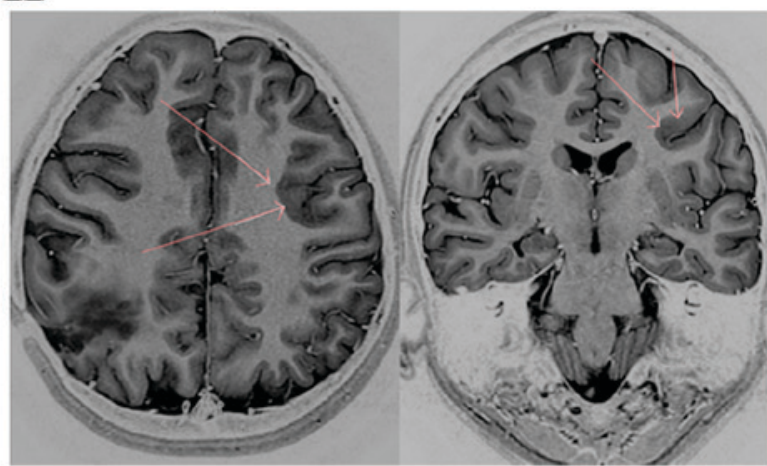

$\mathbf{K}$

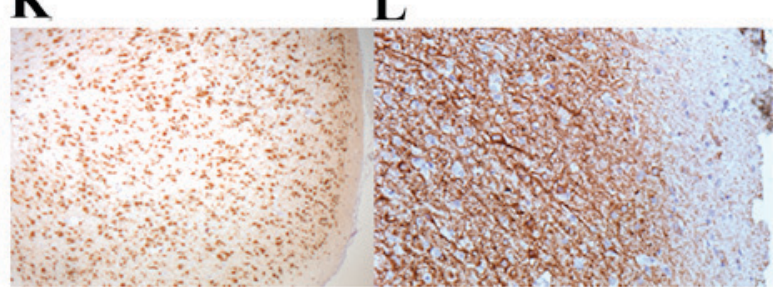

Figure 1. Patient characteristics. For patient 1: (A) The EEG revealed rhythmic seizure discharge originating in the right fronto-temporal region. (B) MR image indicating the area of transmantle dysplasia in the right frontal lobe, with vagueness and blurring of the cortico-subcortical interface (arrows). (C and D) Histopathology of cortex morphology revealing delamination of the layers and cortical disorganization, with dysmorphic neurons and balloon cells under hematoxylin and eosin staining. Magnification, x200. Immunohistochemical staining of (E) NeuN, revealing neurons with delamination of the cortical layers (magnification, x20) and (F) vimentin, marking balloon neurons. Magnification, x200. For patient 2: (G) The recorded EEG revealed rhythmic seizure discharge originating in the left anterior quadrant, with a maximum in the left frontal region. (H) MR image revealing heterotopic subcortical and periventricular nodules in the left frontal lobe, with vagueness and blurring of the cortico-subcortical interface (arrows). (I and J) Histopathology of cortex morphology revealing delamination of the layers and cortical disorganization, with dysmorphic neurons and balloon cells under hematoxylin and eosin staining. Magnification, x20 and $\mathrm{x} 200$. Immunohistochemical staining of $(\mathrm{K}) \mathrm{NeuN}$, revealing neurons with delamination of the cortical layers (magnification, x20) and (L) vimentin, marking balloon neurons (magnification, x200). EEG, electroencephalogram; MR, magnetic resonance; NeuN, RNA binding protein, fox-1 homolog 3.

(TRA1-60 and TRA-81 antibodies). Cells were incubated for $2 \mathrm{~h}$ at room temperature, washed twice with PBS, and stained with 4',6-diamidino-2-phenilindol (DAPI; Sigma-Aldrich; Merck Millipore). The images were captured using confocal microscopy Zeiss LSM-5 exciter (Carl Zeiss Group).

Analysis of the AKT and mTOR pathway. The brain tissue was fixed with $4 \%$ buffered formaldehyde for $24 \mathrm{~h}$ at room temperature, embedded in paraffin and sliced into
$5 \mu \mathrm{m}$ sections. The primary antibodies against AKT (cat. no. mAb2920; Cell Signaling Technology, Inc., Danvers, MA USA), phosphorylated-AKT (cat. no. mAb4060; Cell Signaling Technology, Inc.), mTOR (cat. no. mAb2983, Cell Signaling Technology, Inc.) and phosphorylated-mTOR (cat. no. mAb2976, Cell Signaling Technology, Inc.), diluted 1:100 with blocking buffer, were used. The slides were incubated at $4^{\circ} \mathrm{C}$ for $12 \mathrm{~h}$ followed by further incubation with a fluorescein isothiocyanate-conjugated secondary antibody diluted 1:100 
(cat. no. A11029, Invitrogen; Thermo Fisher Scientific, Inc.) for $2 \mathrm{~h}$ at room temperature. The slides were washed with PBS and $0.01 \%$ DAPI was added for nuclear staining. Analysis was performed using a confocal microscope Zeiss LSM-5 (Carl Zeiss Group). For quantitative analysis, 10 visual fields were randomly selected using a $\mathrm{x} 20$ objective lens, with a minimum of 20 DAPI-positive cells. The images were quantified by area marker parameter using Image-Pro Plus 7 software (Media Cybernetics, Inc., Rockville, MD, USA). The quantification area was analyzed using one-way analysis of variance followed by the Tukey post hoc test. Analyses were performed using GraphPad Prism 5.0 software (GraphPad Software, Inc., La Jolla, CA, USA).

\section{Results}

AKT/mTOR pathway analysis. Analysis of the AKT/mTOR pathway in cerebral dysplastic tissue revealed a statistically significant difference between cerebral tissues in the two patients (Fig. 2). The quantified area stained with anti-AKT was 756 and $291 \mu \mathrm{m}^{2}$ in patients 1 and 2 , respectively $(\mathrm{P}=0.006$; Fig. 2), and that of phosphorylated-AKT staining was 974 and $408 \mu \mathrm{m}^{2}$ for patients 1 and 2 , respectively ( $\mathrm{P}=0.004$; Fig. 2$)$. In addition, the mTOR pathway analysis revealed a statistically significant difference between the stained areas in the cerebral tissues from the two patients (mTOR: Patient 1, 1,210 $\mu \mathrm{m}^{2}$; patient 2, $341 \mu \mathrm{m}^{2} ; \mathrm{P}=0.0003$; and phosphorylated-mTOR: Patient 1, $1004 \mu \mathrm{m}^{2}$; patient 2, $507 \mu \mathrm{m}^{2} ; \mathrm{P}=0.004$; Fig. 2).

iPSCs were generated from cellular reprograming of fibroblasts. Clones with the morphological features of embryonic cells were detected on the 13th day following viral transfection. The clones were manually selected and cultured over Matrigel at $\sim$ day 25 . Small clones surrounded by a few fibroblasts were observed on day 13 (Fig. 3A); however, following 20 (Fig. 3B) and 25 (Fig. 3C) days of culture, larger clones with the morphological features of embryonic cells were detected, which still contained fibroblasts. Finally, following a culture over a Matrigel support, a cell clone free of fibroblasts was obtained (Fig. 3D).

The features of embryonic cells were further confirmed following 3 subcultures of the clones over Matrigel with antibodies against the pluripotency markers Nanog, SOX2, OCT4, TRA1-60 and TRA1-81 (Fig. 4). The positive staining characteristics of the embryonic cells confirmed the successful generation of iPSCs derived from fibroblasts from patients with FCD.

\section{Discussion}

Several neural diseases remain poorly understood, in particular those that affect the central nervous system, from the course of embryonic development up to the onset of clinical signs. These diseases represent a huge physical and social burden to patients and families, with high financial costs to public health systems. Although significant advances have been made in understanding the genetic basis of these diseases, clinical classification, patient care and effective treatments remain scarce (14).

Fortunately, the unquestionable advance of methods for iPSC generation and their subsequent differentiation into

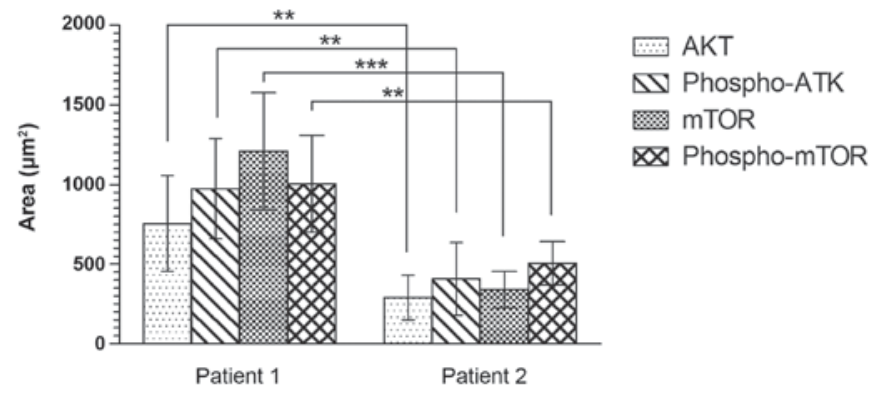

Figure 2. Immunofluorescence analysis of AKT and mTOR expression in dysplastic tissue. A larger area corresponding to phospho- and total AKT and mTOR was observed in patient $1 .{ }^{* *} \mathrm{P}<0.001$ and ${ }^{* * * *} \mathrm{P}<0.0001$ vs. patient 2. AKT, protein kinase B; mTOR, mechanistic target of rapamycin; phospho, phosphorylated.

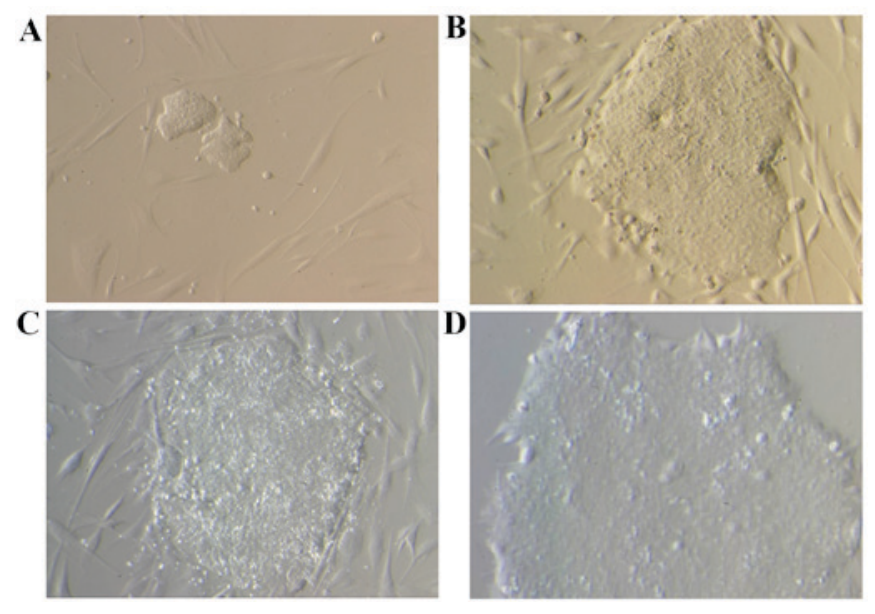

Figure 3. Photomicrography of cell cultures following viral transfection (A) Small clones surrounded by few fibroblasts were observed at day 13 . Larger clones with the morphological features of embryonic cells were detected following (B) 20 and (C) 25 days of culture; however, fibroblasts were still present. (D) Following passage on a Matrigel support, a cell clone free of fibroblasts was obtained. Magnification, x200.

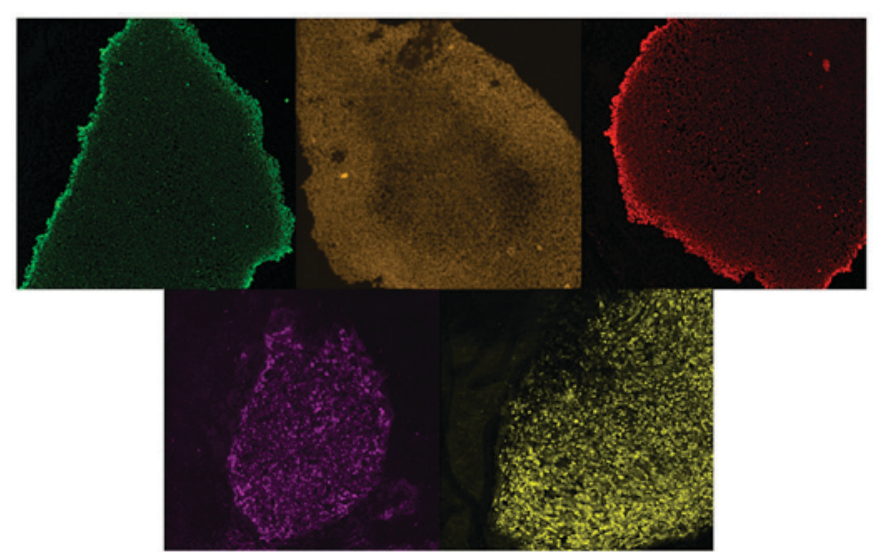

Figure 4. Photomicrography of iPSC clones by confocal microscopy. Antibodies specific to homeobox protein NANOG (green), POU class 5 homeobox 1 (light brown), sex determining region Y-box 2 (red), TRA1-60 (purple) and TRA1-81 (yellow) was used to confirm the embryonic features. Magnification, x200.

several tissue types have rendered these cells a standout cellular model for diverse diseases, including those affecting 
the central nervous system. This strategy allows for the investigation and development of novel approaches to study the mechanisms of embryonic neurodevelopment and pathological contexts specific for each patient, considering their unique genetic backgrounds (14). To the best of our knowledge, the present study is the first to present a method for the generation of a cell model to study the embryonic neurogenesis of epilepsy refractory to drug treatment in the context of FCD.

Previous studies have demonstrated a link between genetic alterations and various types of cortical malformation, which may be specifically associated with the main stages of central nervous system development (8). More than 100 genes have been associated with various types of cortical malformation (50). The major genes identified, including those that are involved in signaling pathways associated with cerebral cortex malformation, are associated with apoptosis, cell proliferation, cytoskeletal structure, cell migration and neurodifferentiation. Alterations in signaling and/or other regulatory pathways may have a variable impact on not only the pattern of brain cortical malformation but also on the site affected (8).

The diagnoses of certain cortical defects, including megalencephaly, polymicrogyria, hemimegalencephaly and cortical dysplasia, are generated following the observation of typical features in clinical imaging. Pathological alterations associated with these disorders include a wide range of abnormalities, including those typically associated with FCD. A growing number of gene alterations have been associated with polymicrogyria and hemimegalencephaly, in particular in cases with more severe phenotypes. Megalencephaly with polymicrogyria has been associated with a mutation in PIK3CA and PIK3R2 genes and isolated hemimegalencephaly has been associated with mosaic mutations in the PI3K, AKT and mTOR pathways. However, unlike these malformations, the etiology of FCD remains unknown (8-10).

Normal PI3K/AKT signaling integrates fundamental physiological responses for healthy aging and longevity. Previous studies have demonstrated that downregulation of the PI3K/AKT signaling pathway may be associated with the lifespan of particular species $(51,52)$. Alterations in the $\mathrm{PI} 3 \mathrm{~K} / \mathrm{AKT} / \mathrm{mTOR}$ signaling pathway are involved in age-related diseases, including heart and neurological conditions. Increased activation of this pathway is considered a feature of early onset Alzheimer's disease, but is also associated with normal aging processes in healthy subjects (53). The brain tissue from the patients investigated in the present study revealed a difference regarding both pathways. A significant increase in AKT, phosphorylated-AKT, mTOR and phosphorylated-mTOR expression was observed in the older patient (patient 1; 45 years old) compared with in the younger patient (patient $2 ; 12$ years old). Indeed, it has previously been reported that balloon and giant cells in the brain tissue from patients with FCD express markers of mature, undifferentiated neuronal cells and glial cells (5). However, it will only be possible to confirm this hypothesis by investigating the brain tissue from patients of the same age, although the effect of genetic background should not be ignored.

It has been hypothesized that clonal somatic mutations are shared among patients with FCD. Previous studies have observed an increase in mTOR signaling in $80-90 \%$ of the balloon cells present in the cortex of patients with FDC Type
IIb. Certain cases of FCD Type IIb also exhibit increased PI3K and AKT activity (8-10). Increased signaling of the PI3K/AKT/mTOR pathway was demonstrated in FCD Types IIa and IIb without genetic mutation, which was attributed to other mechanisms associated with other common diseases (54).

iPSCs are obtained from somatic cells by means of distinct techniques, including chemical induction or gene transfection. Using the premise introduced by Takahashi and Yamanaka (17), at least 4 genes that confer pluripotency should be included for this strategy to be successful. Retroviral vectors require the integration of transfected genes into the host genome in order to be expressed along with the other host genes. Adenoviral, adeno-associated virus and plasmid vectors do not require integration, but may integrate and disrupt the host genome. The viral vectors used in the present study are not integrative and do not influence the genome of the host cell $(55,56)$. This property is an additional advantage to the embryonic features already mentioned, including pluripotency.

The consensus method currently used to characterize pluripotent cells begins with observing the clone morphology. iPSC clones generated from human cells have a distinct morphology, containing large nuclei and well-organized colonies with clearly defined edges (57). In addition, adequate clones should be well organized and tightly adhered, without areas of differentiation. In the present study, the pluripotency of the clones was confirmed by positive expression of Nanog, SOX2, OCT4, TRA1-60 and TRA1-81. There is no minimum criterion required for iPSC characterization. However, the presence of certain markers is essential to confirm the pluripotency, as well as the maintenance of the undifferentiated condition (58).

Gaining a global understanding of the development of normal brain function depends on extensive knowledge concerning brain formation, connection patterns between neurons and brain regions, and the synaptic communications present in these connections. Studies with iPSCs from patients with FCD will enable investigations of different neurodevelopmental stages, and allow the gathering of molecular and clinical evidence from observations of the affected adult tissue. Furthermore, the generated iPSCs will motivate in vitro studies to determine the processes involved in embryonic neurogenesis and to elucidate potential changes that may be associated with the abnormal development of the cerebral cortex, leading to FCD.

The present study provides a useful tool that may help to understand embryonic brain development associated with the development of FCD, a disease with an unclear genesis. Insight into other diseases may also be achieved using the same approach.

\section{Acknowledgements}

The authors would like to thank the National Council for Scientific and Technological Development (grant no. 457384/2013-1) and the Coordination of Improvement of Higher Level Personnel (grant no. 380095/2014-9) for their financial support.

\section{References}

1. Palmini A, Najm I, Avanzini G, Babb T, Guerrini $R$, Foldvary-Schaefer N, Jackson G, Lüders HO, Prayson R, Spreafico R and Vinters HV: Terminology and classification of the cortical dysplasias. Neurology 62: S2-8, 2004. 
2. Arai A, Saito T, Hanai S, Sukigara S, Nabatame S, Otsuki T, Nakagawa E, Takahashi A, Kaneko Y, Kaido T, et al: Abnormal maturation and differentiation of neocortical neurons in epileptogenic cortical malformation: Unique distribution of layer-specific marker cells of focal cortical dysplasia and hemimegalencephaly. Brain Res 1470: 89-97, 2012.

3. Prayson RA, Spreafico R and Vinters HV: Pathologic characteristics of the cortical dysplasias. Neurosurg Clin N Am 13: 17-25, vii, 2002.

4. Guerrini R, Dobyns WB and Barkovich AJ: Abnormal development of the human cerebral cortex: Genetics, functional consequences and treatment options. Trends Neurosci 31: $154-162,2008$

5. Kabat J and Król P: Focal cortical dysplasia-review. Pol J Radiol 77: 35-43, 2012.

6. Taylor DC, Falconer MA, Bruton CJ and Corsellis JA: Focal dysplasia of the cerebral cortex in epilepsy. J Neurol Neurosurg Psychiatry 34: 369-387, 1971.

7. Blümcke I, Thom M, Aronica E, Armstrong DD, Vinters HV, Palmini A, Jacques TS, Avanzini G, Barkovich AJ, Battaglia G, et al: The clinicopathologic spectrum of focal cortical dysplasias: A consensus classification proposed by an ad hoc Task Force of the ILAE Diagnostic Methods Commission. Epilepsia 52: 158-174, 2011

8. Kuzniecky R: Epilepsy and malformations of cortical development: New developments. Curr Opin Neurol 28: 151-157, 2015.

9. Hsu PP, Kang SA, Rameseder J, Zhang Y, Ottina KA, Lim D, Peterson TR, Choi Y, Gray NS, Yaffe MB, et al: The mTOR-regulated phosphoproteome reveals a mechanism of mTORC1-mediated inhibition of growth factor signaling. Science 332: 1317-1322, 2011.

10. Zhou J, Blundell J, Ogawa S, Kwon CH, Zhang W, Sinton C Powell CM and Parada LF: Pharmacological inhibition of mTORC1 suppresses anatomical, cellular, and behavioral abnormalities in neural-specific Pten knock-out mice. J Neurosci 29: 1773-1783, 2009.

11. Cantley LC: The phosphoinositide 3-kinase pathway. Science 296: 1655-1657, 2002

12. Dolmetsch R and Geschwind DH: The human brain in a dish: The promise of iPSC-derived neurons. Cell 145: 831-834, 2011.

13. Dragunow M: The adult human brain in preclinical drug development. Nat Rev Drug Discov 7: 659-666, 2008

14. Ichida JK and Kiskinis E: Probing disorders of the nervous system using reprogramming approaches. EMBO J 34 $1456-1477,2015$.

15. Takahashi K, Okita K, Nakagawa M and Yamanaka S: Induction of pluripotent stem cells from fibroblast cultures. Nat Protoc 2 : 3081-3089, 2007

16. Marinowic DR, Domingues MF, Machado DC and DaCosta JC: The expression of pluripotency genes and neuronal markers after neurodifferentiation in fibroblasts co-cultured with human umbilical cord blood mononuclear cells. In Vitro Cell Dev Biol Anim 51: 26-35, 2015.

17. Takahashi $\mathrm{K}$ and Yamanaka S: Induction of pluripotent stem cells from mouse embryonic and adult fibroblast cultures by defined factors. Cell 126: 663-676, 2006.

18. Takahashi K, Tanabe K, Ohnuki M, Narita M, Ichisaka T, Tomoda K and Yamanaka S: Induction of pluripotent stem cells from adult human fibroblasts by defined factors. Cell 131 : 861-872, 2007.

19. Fries KM, Blieden T, Looney RJ, Sempowski GD, Silvera MR, Willis RA and Phipps RP: Evidence of fibroblast heterogeneity and the role of fibroblast subpopulations in fibrosis. Clin Immunol Immunopathol 72: 283-292,1994.

20. Parent JM and Anderson SA: Reprogramming patient-derived cells to study the epilepsies. Nat Neurosci 18: 360-366, 2015.

21. Song B, Sun G, Herszfeld D, Sylvain A, Campanale NV, Hirst CE, Caine S, Parkington HC, Tonta MA, Coleman HA, et al: Neural differentiation of patient specific iPS cells as a novel approach to study the pathophysiology of multiple sclerosis. Stem Cell Res 8: 259-273, 2012

22. Luo Y, Fan Y, Zhou B, Xu Z, Chen Y and Sun X: Generation of induced pluripotent stem cells from skin fibroblasts of a patient with olivopontocerebellar atrophy. Tohoku J Exp Med 226: 151-159, 2012.

23. Israel MA, Yuan SH, Bardy C, Reyna SM, Mu Y, Herrera C, Hefferan MP, Van Gorp S, Nazor KL, Boscolo FS, et al: Probing sporadic and familial Alzheimer's disease using induced pluripotent stem cells. Nature 482: 216-220, 2012.
24. Yagi T, Ito D, Okada Y, Akamatsu W, Nihei Y, Yoshizaki T, Yamanaka S, Okano $\mathrm{H}$ and Suzuki N: Modeling familial Alzheimer's disease with induced pluripotent stem cells. Hum Mol Genet 20: 4530-4539, 2011.

25. Hossini AM, Megges M, Prigione A, Lichtner B, Toliat MR, Wruck W, Schröter F, Nuernberg P, Kroll H, Makrantonaki E, et al: Induced pluripotent stem cell-derived neuronal cells from a sporadic Alzheimer's disease donor as a model for investigating AD-associated gene regulatory networks. BMC Genomics 16: $84,2015$.

26. Duan L, Bhattacharyya BJ, Belmadani A, Pan L, Miller RJ and Kessler JA: Stem cell derived basal forebrain cholinergic neurons from Alzheimer's disease patients are more susceptible to cell death. Mol Neurodegener 9: 3, 2014.

27. Marchetto MC, Carromeu C, Acab A, Yu D, Yeo GW, Mu Y, Chen G, Gage FH and Muotri AR: A model for neural development and treatment of Rett syndrome using human induced pluripotent stem cells. Cell 143: 527-539, 2010.

28. Williams EC, Zhong X, Mohamed A, Li R, Liu Y, Dong Q, Ananiev GE, Mok JC, Lin BR, Lu J, et al: Mutant astrocytes differentiated from Rett syndrome patients-specific iPSCs have adverse effects on wild-type neurons. Hum Mol Genet 23: 2968-2980, 2014.

29. Djuric U, Cheung AY, Zhang W, Mok RS, Lai W, Piekna A, Hendry JA, Ross PJ, Pasceri P, Kim DS, et al: MECP2e1 isoform mutation affects the form and function of neurons derived from Rett syndrome patient iPS cells. Neurobiol Dis 76: 37-45, 2015

30. Livide G, Patriarchi T, Amenduni M, Amabile S, Yasui D, Calcagno E, Lo Rizzo C, De Falco G, Ulivieri C, Ariani F, et al: GluD1 is a common altered player in neuronal differentiation from both MECP2-mutated and CDKL5-mutated iPS cells. Eur J Hum Genet 23: 195-201, 2015.

31. Sareen D, O'Rourke JG, Meera P, Muhammad AK, Grant S, Simpkinson M, Bell S, Carmona S, Ornelas L, Sahabian A, et al: Targeting RNA foci in iPSC-derived motor neurons from ALS patients with a C9ORF72 repeat expansion. Sci Transl Med 5: 208ra149, 2013

32. Wainger BJ, Kiskinis E, Mellin C, Wiskow O, Han SS, Sandoe J, Perez NP, Williams LA, Lee S, Boulting G, et al: Intrinsic membrane hyperexcitability of amyotrophic lateral sclerosis patient-derived motor neurons. Cell Rep 7: 1-11, 2014.

33. Kiskinis E, Sandoe J, Williams LA, Boulting GL, Moccia R, Wainger BJ, Han S, Peng T, Thams S, Mikkilineni S, et al: Pathways disrupted in human ALS motor neurons identified through genetic correction of mutant SOD1. Cell Stem Cell 14: 781-795, 2014.

34. Devlin AC, Burr K, Borooah S, Foster D, Cleary EM, Geti I, Vallier L, Shaw CE, Chandran S and Miles GB: Human iPSC-derived motoneurons harbouring TARDBP or C9ORF72 ALS mutations are dysfunctional despite maintaining viability. Nat Commun 6: 5999, 2015.

35. Lee P, Martin NT, Nakamura K, Azghadi S, Amiri M, Ben-David U, Perlman S, Gatti RA, Hu H and Lowry WE: SMRT compounds abrogate cellular phenotypes of ataxia telangiectasia in neural derivatives of patient-specific hiPSCs. Nat Commun 4: 1824,2013

36. Jiao J, Yang Y, Shi Y, Chen J, Gao R, Fan Y, Yao H, Liao W, Sun XF and Gao S: Modeling Dravet syndrome using induced pluripotent stem cells (iPSCs) and directly converted neurons. Hum Mol Genet 22: 4241-4252, 2013.

37. Lee G, Papapetrou EP, Kim H, Chambers SM, Tomishima MJ, Fasano CA, Ganat YM, Menon J, Shimizu F, Viale A, et al: Modelling pathogenesis and treatment of familial dysautonomia using patient-specific iPSCs. Nature 461: 402-406, 2009.

38. Doers ME, Musser MT, Nichol R, Berndt ER, Baker M, Gomez TM, Zhang SC, Abbeduto L and Bhattacharyya A: iPSC-derived forebrain neurons from FXS individuals show defects in initial neurite outgrowth. Stem Cells Dev 23: $1777-1787,2014$

39. Tiscornia G, Vivas EL, Matalonga L, Berniakovich I, Barragán Monasterio M, Eguizábal C, Gort L, González F, Ortiz Mellet C, García Fernández JM, et al: Neuronopathic Gaucher's disease: Induced pluripotent stem cells for disease modelling and testing chaperone activity of small compounds. Hum Mol Genet 22: 633-645, 2013

40. Guo X, Disatnik MH, Monbureau M, Shamloo M, Mochly-Rosen D and Qi X: Inhibition of mitochondrial fragmentation diminishes Huntington's disease-associated neurodegeneration. J Clin Invest 123: 5371-5388, 2013. 
41. Yao Y, Cui X, Al-Ramahi I, Sun X, Li B, Hou J, Difiglia M, Palacino J, Wu ZY, Ma L, et al: A striatal-enriched intronic GPCR modulates huntingtin levels and toxicity. Elife 4, 2015.

42. Mekhoubad S, Bock C, de Boer AS, Kiskinis E, Meissner A and Eggan K: Erosion of dosage compensation impacts human iPSC disease modeling. Cell Stem Cell 10: 595-609, 2012.

43. Lancaster MA, Renner M, Martin CA, Wenzel D, Bicknell LS, Hurles ME, Homfray T, Penninger JM, Jackson AP and Knoblich JA: Cerebral organoids model human brain development and microcephaly. Nature 501: 373-379, 2013.

44. Reinhardt P, Schmid B, Burbulla LF, Schöndorf DC, Wagner L, Glatza M, Höing S, Hargus G, Heck SA, Dhingra A, et al: Genetic correction of a LRRK2 mutation in human iPSCs links parkinsonian neurodegeneration to ERK-dependent changes in gene expression. Cell Stem Cell 12: 354-367, 2013.

45. Chung CY, Khurana V, Auluck PK, Tardiff DF, Mazzulli JR, Soldner F, Baru V, Lou Y, Freyzon Y, Cho S, et al: Identification and rescue of $\alpha$-synuclein toxicity in Parkinson patient-derived neurons. Science 342: 983-987, 2013.

46. Sanders LH, Laganière J, Cooper O, Mak SK, Vu BJ, Huang YA, Paschon DE, Vangipuram M, Sundararajan R, Urnov FD, et al: LRRK2 mutations cause mitochondrial DNA damage in iPSC-derived neural cells from Parkinson's disease patients: Reversal by gene correction. Neurobiol Dis 62: 381-386, 2014.

47. Robicsek O, Karry R, Petit I, Salman-Kesner N, Müller FJ, Klein E, Aberdam D and Ben-Shachar D: Abnormal neuronal differentiation and mitochondrial dysfunction in hair follicle-derived induced pluripotent stem cells of schizophrenia patients. Mol Psychiatry 18: 1067-1076, 2013

48. Yoon KJ, Nguyen HN, Ursini G, Zhang F, Kim NS, Wen Z, Makri G, Nauen D, Shin JH, Park Y, et al: Modeling a genetic risk for schizophrenia in iPSCs and mice reveals neural stem cell deficits associated with adherens junctions and polarity. Cell Stem Cell 15: 79-91, 2014.

49. Paulsen Bda S, de Moraes Maciel R, Galina A, Souza da Silveira M, dos Santos Souza C, Drummond H, Nascimento Pozzatto E, Silva H Jr, Chicaybam L, Massuda R, et al: Altered oxygen metabolism associated to neurogenesis of induced pluripotent stem cells derived from a schizophrenic patient. Cell Transplant 21: 1547-1559, 2012.
50. Guerrini R and Dobyns WB: Malformations of cortical development: Clinical features and genetic causes. Lancet Neurol 13: 710-726, 2014

51. Johnson TE: Caenorhabditis elegans 2007: The premier model for the study of aging. Exp Gerontol 43: 1-4, 2008.

52. Kenyon CJ: The genetics of ageing. Nature 464: 504-512, 2010.

53. O'Neill C: PI3-kinase/Akt/mTOR signaling: Impaired on/off switches in aging, cognitive decline and Alzheimer's disease. Exp Gerontol 48: 647-653, 2013.

54. Jansen LA, Mirzaa GM, Ishak GE, O'Roak BJ, Hiatt JB, Roden WH, Gunter SA, Christian SL, Collins S, Adams C, et al: PI3K/AKT pathway mutations cause a spectrum of brain malformations from megalencephaly to focal cortical dysplasia. Brain 138: 1613-1628, 2015.

55. Fusaki N, Ban H, Nishiyama A, Saeki K and Hasegawa M: Efficient induction of transgene-free human pluripotent stem cells using a vector based on Sendai virus, an RNA virus that does not integrate into the host genome. Proc Jpn Acad Ser B Phys Biol Sci 85: 348-362, 2009.

56. Li HO, Zhu YF, Asakawa M, Kuma H, Hirata T, Ueda Y, Lee YS Fukumura M, Iida A, Kato A, et al: A cytoplasmic RNA vector derived from nontransmissible Sendai virus with efficient gene transfer and expression. J Virol 74: 6564-6569, 2000.

57. International Stem Cell Banking Initiative, Andrews PW, Arias-Diaz J, Auerbach J, Alvarez M, Ahrlund-Richter L, Baker D, Benvenisty N, Ben-Josef D, Blin G, et al: Consensus guidance for banking and supply of human embryonic stem cell lines for research purposes. Stem Cell Rev 5: 301-314, 2009.

58. Asprer JS and Lakshmipathy U: Current methods and challenges in the comprehensive characterization of human pluripotent stem cells. Stem Cell Rev 11: 357-372, 2015. 